\title{
Insecticide resistance status of Aedes aegypti and Aedes albopictus mosquitoes in Papua New Guinea
}

\author{
Samuel Demok', Nancy Endersby-Harshman², Rebecca Vinit', Lincoln Timinao 1,3, Leanne J. Robinson 1,4,
} Melinda Susapu ${ }^{5}$, Leo Makita ${ }^{5}$, Moses Laman ${ }^{1}$, Ary Hoffmann² and Stephan Karl1, ${ }^{1 *}$

\begin{abstract}
Background: Aedes aegypti and Ae. albopictus are important vectors of infectious diseases, especially those caused by arboviruses such as dengue, chikungunya and Zika. Aedes aegypti is very well adapted to urban environments, whereas Ae. albopictus inhabits more rural settings. Pyrethroid resistance is widespread in these vectors, but limited data exist from the Southwest Pacific Region, especially from Melanesia. While Aedes vector ecology is well documented in Australia, where incursion of Ae. albopictus and pyrethroid resistance have so far been prevented, almost nothing is known about Aedes populations in neighbouring Papua New Guinea (PNG). With pyrethroid resistance documented in parts of Indonesia but not in Australia, it is important to determine the distribution of susceptible and resistant Aedes populations in this region.
\end{abstract}

Methods: The present study was aimed at assessing Aedes populations for insecticide resistance in Madang and Port Moresby, located on the north and south coasts of PNG, respectively. Mosquitoes were collected using ovitraps and reared in an insectary. Standard WHO bioassays using insecticide-treated filter papers were conducted on a total of $253 \mathrm{Ae}$. aegypti and $768 \mathrm{Ae}$. albopictus adult mosquitoes. Subsets of samples from both species ( $55 \mathrm{Ae}$. aegypti and 48 Ae. albopictus) were screened for knockdown resistance mutations in the voltage-sensitive sodium channel (Vssc) gene, the target site of pyrethroid insecticides.

Results: High levels of resistance against pyrethroids were identified in Ae. aegypti from Madang and Port Moresby. Aedes albopictus exhibited susceptibility to pyrethroids, but moderate levels of resistance to DDT. Mutations associated with pyrethroid resistance were detected in all Ae. aegypti samples screened. Some genotypes found in the present study had been observed previously in Indonesia. No Vssc mutations associated with pyrethroid resistance were found in the Ae. albopictus samples.

Conclusions: To our knowledge, this is the first report of pyrethroid resistance in Ae. aegypti mosquitoes in PNG. Interestingly, usage of insecticides in PNG is low, apart from long-lasting insecticidal nets distributed for malaria control. Further investigations on how these resistant Ae. aegypti mosquito populations arose in PNG and how they are being sustained are warranted.

Keywords: Aedes aegypti, Aedes albopictus, Pyrethroid resistance, Deltamethrin, Papua New Guinea, Port Moresby, Madang, Bioassay, Insecticide

\footnotetext{
*Correspondence: stephan.karl@jcu.edu.au

${ }^{3}$ Australian Institute of Tropical Health and Medicine, James Cook

University, 1/14-88 McGregor Road, Smithfield, QLD 4870, Australia

Full list of author information is available at the end of the article
} 


\section{Background}

Aedes aegypti and Ae. albopictus are vectors of important neglected infectious diseases, especially those caused by arboviruses such as dengue, chikungunya and Zika. They are known to be invasive and have expanded to several new regions relatively recently [1-5].

Insecticide resistance, especially against pyrethroids, is a major threat to vector-borne disease control worldwide. Aedes aegypti is well-adapted to urban habitats, and as a result, is usually more likely to be exposed to insecticides and develop resistance than is Ae. albopictus [6].

In the Asia-Pacific Region, reports have confirmed pyrethroid resistance in Aedes populations in many countries [7], and there is a geographical divide between regions where Aedes spp. are still susceptible (mainly Australia [8]) and those where Aedes spp. are resistant [8]. Aedes albopictus has not established populations in Australia so far [9].

While there are studies from parts of Indonesia indicating pyrethroid resistance in Ae. aegypti [10], Papua New Guinea (PNG) is one of the missing links in the region, where vector distribution and insecticide resistance status are almost completely unknown. While information about the vectors is very scarce [5], it is known that arboviruses represent a significant health burden in PNG; dengue viruses 1-4 circulate in the country and chikungunya outbreaks have been documented [11-13]. Due to the size of PNG, as well as its central location in the South Pacific Region, rapid population growth and increasing economic importance, understanding Aedes vector biology and resistance status in PNG is likely to be relevant to vector-control efforts in the South Pacific Region more generally. For instance, Aedes mosquitoes (and their resistance genes) may be transported from PNG to neighbouring countries, including Australia. Mosquito incursions to Australia are intercepted on a regular basis [14]. Aedes aegypti is present both in the Torres Strait and on the Australian mainland, but no phenotypic resistance or voltage-sensitive sodium channel (Vssc) resistance mutations have been detected in mosquitoes from these locations [8]. Although Ae. albopictus have not yet colonised the Australian mainland, they are present in the Torres Strait and PNG likely provides an important incursion route for this species $[9,15]$.

PNG exhibits a highly complex geography and a low level of urbanisation, with an estimated $13 \%$ of the population residing in urban areas [16]. However, this is rapidly changing as the expansion of urbanised areas, urban drift and anthropogenic environmental transformation are resulting in an increased proportion of humans at high risk from Aedes vector borne diseases. There is no widespread usage of insecticides in PNG in the public sector, apart from mass distribution of long-lasting insecticidal nets (LLIN) for malaria control since around 2009 [17], although large cities such as Port Moresby are not included in LLIN mass distributions. The LLIN distributed in PNG are treated with deltamethrin, which is a type 2 pyrethroid. In the private sector, insecticide usage is also limited, but not well documented. Largescale commercial agriculture is not widespread and only a very small proportion of the available land (c.2.5\%) is commercially farmed. Mining companies use fogging and indoor residual spraying (IRS) to protect their workforce from malaria. Hotels and businesses also engage in smallscale vector control activities, usually by hiring local pest control services. As such, there is potential for insecticide pressures in some areas in PNG to be underestimated.

The aim of this study was to generate initial information about Aedes vectors in PNG and their resistance levels to begin to address the knowledge gaps around these species. We collected Aedes mosquitoes from two population centres, Madang and Port Moresby, to determine species distribution and insecticide resistance status using bioassays to determine phenotype and DNA-based techniques to detect genetic markers of resistance.

\section{Methods}

\section{Sampling sites and sample collection}

Mosquitoes were collected as eggs and larvae in ovitraps placed in different locations around the provincial capital of Madang and the national capital of Port Moresby. In Madang, ovitraps $(n=15-20)$ were placed in the same locations every month for 12 months from February 2018 to January 2019. In Port Moresby traps were only placed once in December $2018(n=20)$. In both locations, traps were spread out across a large area in residential properties and hotel grounds, protected from rain. Trap contents were collected 5-7 days after trap placement.

\section{Mosquito rearing and bioassays}

Mosquitoes were reared to adult stage in a permanent (Madang) or temporary (Port Moresby) insectary. Bioassays were conducted as previously described [18] using WHO standard methodology, and limiting concentration filter papers obtained from School of Biological Sciences, Universiti Sains Malaysia, which is the regional centre manufacturing these commodities. Assays were always accompanied by at least one control of 20 mosquitoes (20 per cylinder). Where possible each test included 20 mosquitoes per assay ( 20 per cylinder). Ideally, we conducted 4 assays and 2 controls per insecticide in parallel; however, this was not always possible given the limited mosquito numbers. The average humidity in the assays was $76.1 \%$ (range: $67.8-82.3 \%$ ) and the average temperature was $27.03{ }^{\circ} \mathrm{C}$ (range: $22.6-32.0^{\circ} \mathrm{C}$ ). In Madang, PNG, 
day length varies from approximately $12.35 \mathrm{~h}$ in winter to $13.10 \mathrm{~h}$ in summer (southern hemisphere).

Insecticides used in this study were deltamethrin (0.05\%), DDT (4\%) lambdacyhalothrin (0.05\%), bendiocarb $(0.1 \%)$ and malathion (5\%). Aedes aegypti and Ae. albopictus were exposed to the filter papers as per standard protocol for $60 \mathrm{~min}$, and then removed, and placed into holding cups with access to sugar solution for $24 \mathrm{~h}$. Outcome variables were the proportion of mosquitoes knocked down after 60 min and the proportion of mosquitoes dead after the $24 \mathrm{~h}$ holding period. Since DDT has been shown to act more slowly on anophelines, we also assessed mortality $48 \mathrm{~h}$ after exposure [19].

In PNG, Ae. albopictus and Ae. aegypti occur mixed in containers and separation of live larvae or adults prior to conducting the bioassays is not possible. Therefore, we conducted the assays with mixed species and identified the adults morphologically after the assays.

\section{Molecular analysis of kdr mutations}

DNA was extracted from whole female mosquitoes using the High Pure PCR Template Preparation Kit (Roche, Millers Point, NSW, Australia) and suspended in $200 \mu \mathrm{l}$ elution buffer. A 1:5 DNA dilution in PCR-grade $\mathrm{H}_{2} \mathrm{O}$ was prepared.

TaqMan $^{\circledR}$ (Life Technologies Corporation, Mulgrave, VIC, Australia) assays were used to identify mutations in codons 989, 1016 and 1534 in the Vssc gene (numbered according to sequence of the most abundant splice variant of the house fly, Musca domestica) of Ae. aegypti. Primer and probe sequences used are as follows: Codon 989, forward primer (5'-TTC ATG ATC GTG TTC CGG GTA TT-3'), reverse primer (5'-ACG TCA CCC ACA AGC ATA CAA T-3'), probe (wildtype) (5'-CCC ACA TGG ATT CGA T-3'), probe (mutant) (5'-CCA CAT GGG TTC GAT-3'); codon 1016, forward primer (5'CGT GCT AAC CGA CAA ATT GTT TCC-3'), reverse primer (5'-ATG AAC CGA AAT TGG ACA AAA GCA A-3'), probe (wildtype) (5'-AGA AAA GGT TAA GTA CCT GTG CG-3'), probe (mutant) (5'-AAG GTT AAG TCC CTG TGC G-3'); codon 1534, forward primer (5'TCT ACA TGT ACC TCT ACT TTG TGT TCT TCA$\left.3^{\prime}\right)$, reverse primer (5'-GAT GAT GAC ACC GAT GAA CAG ATT $\mathrm{C}-3^{\prime}$ ), probe (wildtype) (5'-AAC GAC CCG AAG ATG A-3'), probe (mutant) (5'-ACG ACC CGC AGA TGA-3'). A $7 \mu \mathrm{l}$ PCR reaction contained $40 \times$ TaqMan ${ }^{\circledR}$ assay $(0.17 \mu \mathrm{l}), 2 \times$ KAPA Fast PCR Probe Force qPCR Master Mix (KAPA Biosystems Inc.) $(3.50 \mu \mathrm{l})$, $\mathrm{ddH}_{2} \mathrm{O}(1.33 \mu \mathrm{l})$ and genomic DNA (1:5 dilution) $(2 \mu \mathrm{l})$.

Assays for each Vssc mutation were run in triplicate on a LightCycler ${ }^{\circledR}$ II 480 (Roche, Millers Point, NSW, Australia) instrument in 384-well plates with a pre-incubation of $3 \mathrm{~min}$ at $98{ }^{\circ} \mathrm{C}\left(\mathrm{ramp}\right.$ rate $\left.4.8{ }^{\circ} \mathrm{C} / \mathrm{s}\right)$ followed by
40 cycles of amplification at $95^{\circ} \mathrm{C}$ for $10 \mathrm{~s}\left(2.5^{\circ} \mathrm{C} / \mathrm{s} \mathrm{ramp}\right.$ rate) and $60{ }^{\circ} \mathrm{C}$ for $20 \mathrm{~s}\left(2.5^{\circ} \mathrm{C} / \mathrm{s}\right.$ ramp rate) (acquisition mode: single) with a final cooling step of $37^{\circ} \mathrm{C}$ for $1 \mathrm{~min}$ $\left(2.5^{\circ} \mathrm{C} / \mathrm{s}\right.$ ramp rate). Endpoint genotyping was conducted for each mutation site (Roche LightCycler ${ }^{\circledR} 480$ Software Version 1.5.1.62).

Mutations at Vssc codon 1534 in S6, Domain III of Ae. albopictus were screened using a forward primer of our own design (Alb171F: 5'-CCG ATT CGC GAG ACC AAC AT-3') and the reverse primer of Kasai et al. (2011) (aegSCR8) [20]. Primer Alb171F was designed in the exon that contains Vssc codon 1534 in order to alleviate problems we encountered in sequencing across the intron. A $25 \mu \mathrm{l}$ PCR mix included final concentrations of ThermoPol buffer Mg-free $(1 \times)$ (New England Biolabs, Ipswich, MA, USA), dNTPs (200 $\mu \mathrm{M}$ each), $\mathrm{MgCl}_{2}(1.5$ $\mathrm{mM}), 0.5 \mu \mathrm{M}$ each of forward and reverse primers, 0.625 units of Immolase ${ }^{\mathrm{TM}}$ Taq polymerase (Bioline, London, UK), $2 \mu$ l genomic DNA (Chelex ${ }^{\circledR}$ extraction) diluted 1:10 and PCR-grade $\mathrm{H}_{2} \mathrm{O}$ to a final volume of $25 \mu \mathrm{l}$.

PCR conditions used to amplify the region were an initial denaturation at $95{ }^{\circ} \mathrm{C}$ for $10 \mathrm{~min}, 35$ cycles of $95{ }^{\circ} \mathrm{C}$ for $30 \mathrm{~s}$, annealing at $52{ }^{\circ} \mathrm{C}$ for $45 \mathrm{~s}$ and extension at $72{ }^{\circ} \mathrm{C}$ for $45 \mathrm{~s}$, followed by a final extension step of $5 \mathrm{~min}$ at $72{ }^{\circ} \mathrm{C}$ and a hold at $10^{\circ} \mathrm{C}$.

PCR amplicons (220 bp) were sent to Macrogen Inc. in Seoul, Korea, for sequencing on a 3730xl DNA analyser. Sequences (up to $180 \mathrm{bp}$ ) were aligned and analysed using Geneious ${ }^{\circledR}$ 11.1.4 (Biomatters Ltd.) and mapped to a reference sequence (GenBank: KC152046.1).

\section{Results}

\section{Overall species distribution}

In Madang Ae. albopictus was observed to be the dominant species, whereas in Port Moresby Ae. aegypti was more abundant. Relative abundance of Ae. aegypti vs Ae. albopictus in December 2018, when mosquitoes were trapped in both locations simultaneously, was $19.6 \mathrm{vs}$ $80.4 \%$ in Madang and 81.1 vs 18.9 \% in Port Moresby, respectively, as shown in Fig. 1.

\section{Bioassays}

Overall, 1021 female Ae. aegypti and Ae. albopictus mosquitoes were exposed to insecticides in the bioassays ( $n=253$ Ae. aegypti and $n=768$ Ae. albopictus, excluding negative controls done alongside each assay). A total of 26 bioassays were conducted: with deltamethrin $(0.05 \%)$ $(n=10)$; with DDT $(4 \%)(n=5)$; with lambda-cyhalothrin $(0.05 \%)(n=5)$; with bendiocarb $(0.1 \%)(n=3)$; and with malathion $(5 \%)(n=3)$. In Port Moresby, only two bioassays with deltamethrin were conducted. The results of the bioassays are presented in Tables 1 and 2 for Ae. aegypti and Ae albopictus, respectively. 


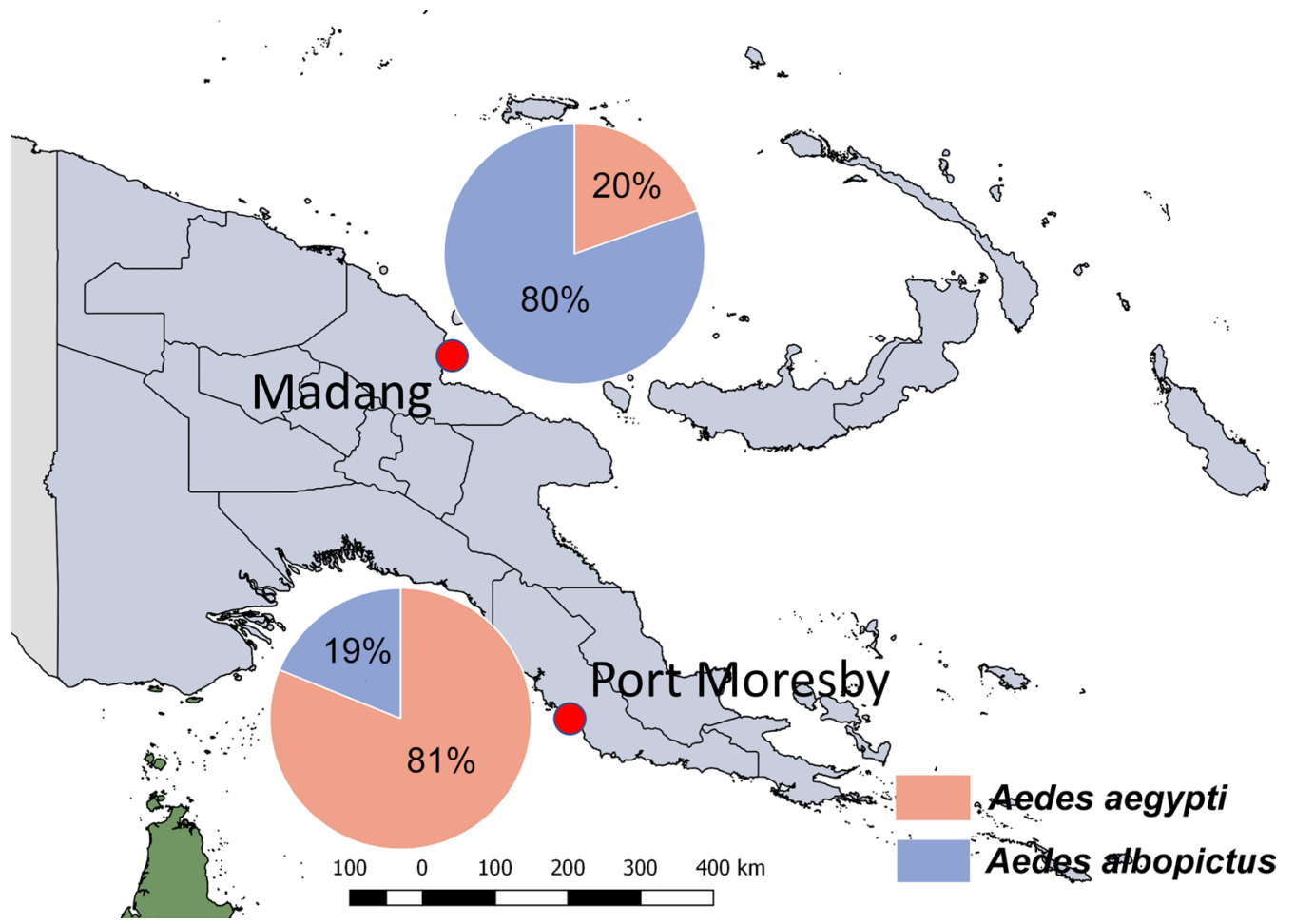

Fig. 1 Location of the study sites and relative distribution of Aedes spp. in December 2018

Table 1 Bioassay results for Aedes aegypti, including samples collected in Madang and Port Moresby. Values are given as proportions and $95 \% \mathrm{Cl}[35]$

\begin{tabular}{llr}
\hline Insecticide, location & Mean knockdown after 60 min $(95 \% \mathrm{Cl})$ & $\begin{array}{c}\text { Mean mortality } \\
\text { after } 24 \mathrm{~h}(95 \% \\
\mathrm{Cl})\end{array}$ \\
\hline 0.05\% deltamethrin, Madang $(n=106)$ & $0.29(0.21-0.39)$ & $0.33(0.25-0.42)$ \\
$0.05 \%$ deltamethrin, Port Moresby $(n=46)$ & $0.13(0.06-0.26)$ & $0.07(0.02-0.18)$ \\
$0.05 \%$ lambda-cyhalothrin, Madang $(n=37)$ & $0.11(0.04-0.25)$ & $0.32(0.20-0.49)$ \\
$0.1 \%$ bendiocarb, Madang $(n=18)^{\mathrm{a}}$ & $0.89(0.66-0.98)$ & $0.89(0.66-0.98)$ \\
$4 \%$ DDT, Madang $(n=13)^{\mathrm{a}}$ & $0(0-0.27)$ & $0(0-0.27)$ \\
$5 \%$ malathion, Madang $(n=33)$ & $1.00(0.88-1.00)$ & $1.00(0.88-1.00)$
\end{tabular}

a The numbers of Ae. aegypti mosquitoes tested against Bendiocarb $(n=18)$ and DDT $(n=13)$ in Madang are too low to be statistically robust and these results are included for reason of completeness

Abbreviations: $\mathrm{n}$, number of mosquitoes; $\mathrm{Cl}$, confidence interval

These data clearly show high levels pyrethroid resistance in both Madang and Port Moresby Ae. aegypti populations. The Ae. aegypti population in Port Moresby seems to exhibit a higher level of resistance than that in Madang, with less than $10 \%$ of mosquitoes dying during the $24 \mathrm{~h}$ holding period after exposure to deltamethrin. Similarly, susceptibility to lambda-cyhalothrin and DDT was greatly reduced (although the number of Ae. aegypti exposed to DDT was low). Susceptibility against carbamates (bendiocarb) and organophosphates (malathion) was present in the Madang population (Port Moresby population not tested), but since the number of exposed mosquitoes was low, this result should be treated cautiously.

Susceptibility to DDT of Ae. albopictus also appeared to be reduced. The cut-off for confirmed resistance is $<90 \%$ mortality over the course of the $24 \mathrm{~h}$ holding period [21]. We observed a 24-h mortality of $0.79(95 \%$ CI: 0.72-0.85). Aedes albopictus were found to be susceptible to pyrethroids, carbamates and organophosphates. 
Table 2 Bioassay results for Aedes albopictus, including samples collected in Madang and Port Moresby. Values are given as proportions and $95 \% \mathrm{Cl}[35]$

\begin{tabular}{llr}
\hline Insecticide, location & Mean knockdown after 60 min $(95 \%$ Cl) & $\begin{array}{c}\text { Mean mortality } \\
\text { after } 24 \mathrm{~h} \mathrm{(95 \%} \\
\mathrm{Cl})\end{array}$ \\
\hline $0.05 \%$ deltamethrin, Madang $(n=273)$ & $0.98(0.96-0.99)$ & $1.00(0.98-1.00)$ \\
$0.05 \%$ deltamethrin, Port Moresby $(n=11)^{\mathrm{a}}$ & $0.92(0.60-1.00)$ & $0.92(0.60-1.00)$ \\
$0.05 \%$ lambda-cyhalothrin, Madang $(n=135)$ & $1.00(0.97-1.00)$ & $1.00(0.97-1.00)$ \\
$0.1 \%$ bendiocarb, Madang $(n=123)$ & $1.00(0.96-1.00)$ & $1.00(0.96-1.00)$ \\
$4 \%$ DDT, Madang $(n=145)^{\mathrm{b}}$ & $0.62(0.54-0.70)$ & $0.79(0.72-0.85)$ \\
$5 \%$ malathion, Madang $(n=81)$ & $0.99(0.93-1.00)$ & $0.96(0.89-0.99)$ \\
\hline
\end{tabular}

a The number of mosquitoes tested against deltamethrin in Port Moresby $(n=11)$ is too low to be statistically robust and these results are included for reason of completeness

b DDT is known to act more slowly [19] in anophelines, even in susceptible populations. Therefore, we also determined $48 \mathrm{~h}$ mortality for most ( $n=129)$ Ae. albopictus mosquitoes exposed to DDT. Mortality after $48 \mathrm{~h}$ was unchanged at $0.77(0.69-0.83)$

Abbreviations: $\mathrm{n}$, number of mosquitoes; $\mathrm{Cl}$, confidence interval

Table 3 Frequencies of Vssc genotypes of 55 Aedes aegypti sampled from Madang, Papua New Guinea

\begin{tabular}{llll}
\hline \multicolumn{4}{l}{ Composite genotypes (V1016G/F1534C/S989P) } \\
\hline GG/TT/CC & GG/TT/TC & TG/TG/TC & TG/TG/TT \\
$0.64(35 / 55)$ & $0.16(9 / 55)$ & $0.11(6 / 55)$ & $0.09(5 / 55)$
\end{tabular}

Notes: Wildtype for V1016G is TT whereas homozygous mutant is GG. Wildtype for F1534C is TT whereas homozygous mutant is GG. Wildtype for V1016G is TT whereas homozygous mutant is CC. No (susceptible) wildtype was observed

\section{Genetic analyses}

A total of 55 randomly selected Ae. aegypti mosquitoes from Madang were tested for sodium channel mutations using TaqMan ${ }^{\circledR}$ probe assays designed for these sites. The para sodium channel or voltage-sensitive sodium channel $(V s s c)$ is the target site for both pyrethroid insecticides and DDT [22]. In addition, 48 Ae. albopictus mosquitoes were screened by sequencing for Vssc mutations at codon 1534, the main site of knockdown resistance mutations in this species [23].

For Ae. aegypti, three sodium channel mutations, V1016G, F1534C and S989P were found resulting in four composite genotypes. Composite genotype frequencies are summarised in Table 3.

The most common genotype (frequency $=0.65$ ) consisted of homozygous mutants at codons 1016 and 989 and the wildtype homozygote at codon 1534 . This is a common genotype also found in Bali and other locations throughout southeast Asia and the Pacific [24]. It confers resistance to both Type I and Type II pyrethroids.

The second most frequent genotype was the triple heterozygote at V1016G, F1534C and S989P (frequency $=0.16$ ). This is also found commonly in Ae. aegypti in other countries in the region and confers a low level of resistance to Type I and II pyrethroids [25].
The remaining two genotypes found were (i) homozygous mutant at codon 1016, wildtype at codon 1534 and heterozygous mutant at codon 989 (frequency: 0.11); and (ii) heterozygous mutants at codons 1016 and 1534, and homozygous wildtype at codon 989 (frequency: 0.09). These genotypes are unusual, but have previously been noted in samples of Ae. aegypti from Yogyakarta, Indonesia [24]. Both these genotypes are expected to confer some level of pyrethroid resistance [26]. There were no susceptible wildtype individuals found in the sample and there is no indication that a wildtype haplotype exists in the population.

DNA sequences around codon 1534 were obtained for 36 Ae. albopictus specimens. None of the specimens showed a mutation within codon 1534 . There were some synonymous mutations in other codons which comprised heterozygotes (IUPAC code $\mathrm{Y}$ for $\mathrm{C} / \mathrm{T}$ ) in nine individuals. Two individuals were homozygous synonymous mutants at codon 1528 and contained a single base mutation from $\mathrm{C}$ to $\mathrm{T}$. The same mutation at this site was observed by Kasai et al. [20], but is not expected to affect susceptibility to pyrethroids. The sequences for the $36 \mathrm{Ae}$. albopictus are provided in Additional file 1.

\section{Discussion}

Insecticide resistance is a threat to vector borne disease control, and pyrethroids are still a widely used insecticide class, e.g. in LLIN for malaria control [27]. Pyrethroid resistance in the highly competent arbovirus vector $A e$. aegypti is widely spread [28], and has also been confirmed in Ae. albopictus [28]. In the Asia-Pacific region, reports have confirmed pyrethroid resistance in Aedes populations in many countries including Indonesia, but not in Australia [8]. This implies that there is a geographical divide somewhere in the region, between areas where 
Aedes populations are still susceptible and those where Aedes populations are resistant $[8,9]$. The present data from Port Moresby and Madang indicate that resistance in urban PNG populations may be widely spread, given that we found strong pyrethroid resistance in urban $A e$. aegypti populations from the north and south coast of the country, and not a single wild type Ae. aegypti among the 55 samples tested. Australia has engaged in programs to prevent an incursion of Ae. albopictus via the Torres Strait for some time [9]. These efforts now seem even more important and should include Ae aegypti, as imported Ae. aegypti originating in PNG may well carry resistant alleles. Other incursion routes from Asia also carry this risk [29].

In contrast to the Ae. aegypti data, we found no genetic mutations known to convey pyrethroid resistance in the Ae. albopictus mosquitoes tested. Moreover, Ae. albopictus mosquitoes were susceptible to deltamethrin and lambda-cyhalothrin in bioassays. We did observe reduced susceptibility of Ae. albopictus against DDT in Madang using bioassays. Similar results have been found in Ae. albopictus from India where DDT resistance is detected in bioassays, but is not associated with Vssc mutations [30]. DDT resistance in Ae. albopictus from PNG either may be persisting following previous use of the compound in the country during the malaria eradication era or may be due to incursion of resistant mosquitoes, an occurrence known from other parts of the world [31, 32].

Aedes aegypti are more prominent in urban than in rural areas, as these mosquitoes are well adapted to habitats found in urban settings [3]. This may account for the much higher proportion of Ae. aegypti found in the highly urbanised environment of the national capital Port Moresby compared with the proportion found in Madang (medium sized town, semi-urban). Aedes albopictus is known to use a wider range of habitats than Ae. aegypti and is better adapted to the natural environment than it is to urban areas.

The observed level of pyrethroid resistance in Ae. aegypti in the two PNG populations is surprising and unexpected, especially as LLIN usage in cities is lower than in rural areas. For example, no LLIN are distributed in Port Moresby (Tim Freeman, Rotary Against Malaria PNG, primary LLIN distribution agency in PNG, personal communication). No detailed analyses that quantify insecticide usage in PNG in the private sector exist, but to the best of our knowledge, insecticide usage is low. Indirect exposure to pesticides through the agricultural sector seems unlikely, particularly as subsistence farming usually does not involve the use of insecticides. Other sources of insecticide use in PNG are mining companies and other large commercial enterprises focused on resource extraction, as well as hotels and smaller businesses. Little is known about private household-based usage of insecticides, but this could provide further selection pressures. It is therefore possible that the observed pyrethroid resistance is focused on larger population centres or other commercial areas.

Another hypothesis arising from this work is that pyrethroid-resistant Ae. aegypti has spread to PNG from neighbouring regions. Human-mediated movement of pyrethroid-resistant Ae. aegypti is known to occur on a regular basis and mosquitoes with resistance alleles and identified, exotic origins are often intercepted at Australian and New Zealand air and sea ports [33]. It is possible that mosquitoes are transported on marine vessels used, e.g. for fishing and logging, as well as container transport [1] and so incursions to PNG could be possible. Pyrethroid resistance in Ae. aegypti is thought to be spreading in some parts of Indonesia [34], so potential sources of resistant mosquitoes in the region around PNG are likely to be on the increase. Further surveillance and sampling in PNG is required to map the level of resistance and population genetics of Ae. aegypti in different parts of the country and identify any potential pathways of incursion.

Limitations of this study include the absence of a susceptible Aedes laboratory strain to be used as a control, one of the challenges of working in a remote area with resource limitations. However, our observations were made on samples collected from multiple sites, tested in multiple assays. Bioassay results are also well supported by the genetic analyses presented. The concentrations on the test papers we used were those recommended for anopheline mosquitoes by WHO, whereas the concentrations (unofficially) recommended for Aedes mosquitoes are actually lower than those for anophelines [21]. As such our study is unlikely to overestimate the level of resistance but may represent an underestimation.

\section{Conclusions}

The present study identified pyrethroid resistance in $A e$. aegypti in two locations in Papua New Guinea. To our knowledge, this is the first Aedes bioassay and $k d r$ genotyping data from mosquito populations in Papua New Guinea. Due to presumably low insecticide usage in PNG, it is currently unclear how pyrethroid resistance in PNG arose and is maintained. Studies that investigate and quantify insecticides in the private sector in PNG are urgently needed. Population genetic studies that investigate the relationship between Aedes vectors in PNG and neighbouring countries would be useful to determine pathways of spread and incursion routes of resistant populations. 


\section{Additional file}

Additional file 1. DNA sequences for 36 individuals of Aedes albopictus for a small section of the voltage-sensitive sodium channel gene (Vssc) from S6, domain III.

\section{Abbreviations}

AE: Aedes; DDT: dichlorodiphenyltrichloroethane; IRS: indoor residual spraying; KDR: knockdown resistance; LLIN: long-lasting insecticidal nets; PNG: Papua New Guinea; VSSC: voltage-sensitive sodium channel; WHO: World Health Organisation.

\section{Acknowledgements}

We would like to thank PNGIMR and Rotary Against Malaria employees for their assistance with placing mosquito traps in their premises in Madang and Port Moresby. We would like to thank Thomas Burkot, Tanya Russell, Scott Ritchie, Uriel Kitron and Tim Freeman for helpful discussions. We thank the Strive PNG partners for their support.

\section{Authors' contributions}

SD, RV and LT: field sample collection by ovitrapping and conduction phenotypic bioassays; data analysis. NEH and $\mathrm{AH}$ : molecular assays and analysis of molecular data, provided expertise with molecular techniques. LR provided expertise with field work and data analysis. SK and ML conceived the study; conducted data analysis; prepared the first manuscript draft; provided expertise with field work. SD, NEH, RV, LT, MS, LM, LJR, ML, AH and SK reviewed and contributed to final manuscript. All authors read and approved the final manuscript.

\section{Funding}

This study received no dedicated funding except that molecular assays were supported by an NHMRC Program grant and AH was supported by an NHMRC Fellowship. SK was supported by an NHMRC Career Development Fellowship GNT1141441, LT was supported by a JCU PhD Scholarship and LJR is supported by an NHMRC Career Development Fellowship. SD was supported, in part, by Strive PNG (Australian Department of Foreign Affairs and Trade).

\section{Availability of data and materials}

The datasets used and/or analysed during the current study are available from the corresponding author on reasonable request. Genetic sequences generated during this study are included in Additional file 1.

\section{Ethics approval and consent to participate}

The present research was approved by the PNGIMR Institutional Review Board and the National Medical Research Advisory Committee of Papua New Guinea (Protocol number 18.10).

\section{Consent for publication}

Not applicable.

\section{Competing interests}

The authors declare that they have no competing interests.

\begin{abstract}
Author details
${ }^{1}$ Vector-Borne Diseases Unit, PNG Institute of Medical Research, P.O. Box 378, Madang 511, Madang Province, Papua New Guinea. ${ }^{2}$ School of BioSciences, Bio21 Institute, The University of Melbourne, 30 Flemington Rd., Parkville, VIC 3010, Australia. ${ }^{3}$ Australian Institute of Tropical Health and Medicine, James Cook University, 1/14-88 McGregor Road, Smithfield, QLD 4870, Australia. ${ }^{4}$ Burnet Institute, 85 Commercial Road, Melbourne, VIC 3004, Australia.

${ }^{5}$ National Department of Health, Waigani Drive, P.O. Box 807, Port Moresby, Papua New Guinea.
\end{abstract}

Received: 25 April 2019 Accepted: 27 June 2019

Published online: 03 July 2019

\section{References}

1. Fonzi E, Higa Y, Bertuso AG, Futami K, Minakawa N. Human-mediated marine dispersal influences the population structure of Aedes aegypti in the Philippine Archipelago. PLoS Negl Trop Dis. 2015;9:e0003829.

2. Hill MP, Axford JK, Hoffmann AA. Predicting the spread of Aedes albopictus in Australia under current and future climates: multiple approaches and datasets to incorporate potential evolutionary divergence. Aust Ecol. 2014;39:469-78.

3. Kraemer MU, Sinka ME, Duda KA, Mylne AQ, Shearer FM, Barker CM, et al. The global distribution of the arbovirus vectors Aedes aegypti and $A e$. albopictus. Elife. 2015;4:e08347.

4. Lounibos LP, Juliano SA. Where vectors collide: the importance of mechanisms shaping the realized niche for modeling ranges of invasive Aedes mosquitoes. Biol Invasions. 2018;20:1913-29.

5. Maynard AJ, Ambrose L, Cooper RD, Chow WK, Davis JB, Muzari MO, et al. Tiger on the prowl: invasion history and spatio-temporal genetic structure of the Asian tiger mosquito Aedes albopictus (Skuse, 1894) in the Indo-Pacific. PLoS Negl Trop Dis. 2017;11:e0005546.

6. Ayorinde A, Oboh B, Oduola A, Otubanjo O. The insecticide susceptibility status of Aedes aegypti (Diptera: Culicidae) in farm and nonfarm sites of Lagos State, Nigeria. J Insect Sci. 2015;15:75.

7. Amelia-Yap ZH, Chen CD, Sofian-Azirun M, Low VL. Pyrethroid resistance in the dengue vector Aedes aegypti in Southeast Asia: present situation and prospects for management. Parasit Vectors. 2018;11:332.

8. Endersby-Harshman NM, Wuliandari JR, Harshman LG, Frohn V, Johnson BJ, Ritchie SA, et al. Pyrethroid susceptibility has been maintained in the dengue vector, Aedes aegypti (Diptera: Culicidae), in Queensland, Australia. J Med Entomol. 2017;54:1649-58.

9. Muzari MO, Devine G, Davis J, Crunkhorn B, van den Hurk A, Whelan $P$, et al. Holding back the tiger: successful control program protects Australia from Aedes albopictus expansion. PLoS Negl Trop Dis. 2017;11:e0005286.

10. Ahmad I, Astari S, Tan M. Resistance of Aedes aegypti (Diptera: Culicidae) in 2006 to pyrethroid insecticides in Indonesia and its association with oxidase and esterase levels. Pak J Biol Sci. 2007;10:3688-92.

11. Senn N, Luang-Suarkia D, Manong D, Siba PM, McBride WJ. Contribution of dengue fever to the burden of acute febrile illnesses in Papua New Guinea: an age-specific prospective study. Am J Trop Med Hyg. 2011;85:132-77.

12. Horwood PF, Reimer LJ, Dagina R, Susapu M, Bande G, Katusele M, et al. Outbreak of chikungunya virus infection, Vanimo, Papua New Guinea. Emerg Infect Dis. 2013;19:1535-8.

13. Moore PR, van den Hurk AF, Mackenzie JS, Pyke AT. Dengue viruses in Papua New Guinea: evidence of endemicity and phylogenetic variation, including the evolution of new genetic lineages. Emerg Microbes Infect. 2017:6(12):e114.

14. Webb C, Doggett SL, Russell R. A guide to mosquitoes of Australia. Clayton: CSIRO Publishing; 2016.

15. van den Hurk AF, Nicholson J, Beebe NW, Davis J, Muzari OM, Russell RC, et al. Ten years of the tiger: Aedes albopictus presence in Australia since its discovery in the Torres Strait in 2005. One Health. 2016;2:19-24.

16. Jones P. Managing urbanisation in Papua New Guinea: planning for planning's sake? The Alfred Deakin Research Institute Working Papers; 2012. p. 33.

17. Reimer LJ, Thomsen EK, Tisch DJ, Henry-Halldin CN, Zimmerman PA, Baea $\mathrm{ME}$, et al. Insecticidal bed nets and filariasis transmission in Papua New Guinea. N Engl J Med. 2013;369:745-53.

18. Koimbu G, Czeher C, Katusele M, Sakur M, Kilepak L, Tandrapah A, et al. Status of insecticide resistance in Papua New Guinea: an update from nation-wide monitoring of Anopheles mosquitoes. Am J Trop Med Hyg. 2017;98:162-5.

19. Lukwa N, Sande S, Munosiyei P, Zimba M. Insecticide susceptibility tests conducted in Kamhororo, Masakadza and Chilonga villages in Zimbabwe during the 2011 malaria period. J Entomol Acarol Res. 2012:44:e19.

20. Kasai S, Ng LC, Lam-Phua SG, Tang CS, Itokawa K, Komagata O, et al. First detection of a putative knockdown resistance gene in major mosquito vector, Aedes albopictus. Jpn J Infect Dis. 2011;64:217-21.

21. WHO. Test procedures for insecticide resistance monitoring in malaria vector mosquitoes. Geneva: World Health Organization; 2013.

22. Soderlund DM, Bloomquist JR. Neurotoxic actions of pyrethroid insecticides. Annu Rev Entomol. 1989:34:77-96. 
23. Xu J, Bonizzoni M, Zhong D, Zhou G, Cai S, Li Y, et al. Multi-country survey revealed prevalent and novel F1534S mutation in voltage-gated sodium channel (VGSC) gene in Aedes albopictus. PLoS Negl Trop Dis. 2016;10:e0004696.

24. Wuliandari JR, Lee SF, White VL, Tantowijoyo W, Hoffmann AA, EndersbyHarshman NM. Association between three mutations, F1565C, V1023G and S996P, in the voltage-sensitive sodium channel gene and knockdown resistance in Aedes aegypti from Yogyakarta, Indonesia. Insects. 2015:6:658-85.

25. Du Y, Nomura Y, Satar G, Hu Z, Nauen R, He SY, et al. Molecular evidence for dual pyrethroid-receptor sites on a mosquito sodium channel. Proc Natl Acad Sci USA. 2013;110:11785-90.

26. Plernsub S, Saingamsook J, Yanola J, Lumjuan N, Tippawangkosol $P_{\text {, }}$ Sukontason K, et al. Additive effect of knockdown resistance mutations, S989P, V1016G and F1534C, in a heterozygous genotype conferring pyrethroid resistance in Aedes aegypti in Thailand. Parasit Vectors. 2016;9:417.

27. Hetzel MW, Pulford J, Ura Y, Jamea-Maiasa S, Tandrapah A, Tarongka N, et al. Insecticide-treated nets and malaria prevalence, Papua New Guinea, 2008-2014. Bull World Health Organ. 2017;95:695-705.

28. Smith LB, Kasai S, Scott JG. Pyrethroid resistance in Aedes aegypti and Aedes albopictus: important mosquito vectors of human diseases. Pestic Biochem Physiol. 2016;133:1-12.

29. Whelan P, Nguyen H, Hajkowicz K, Davis J, Smith D, Pyke A, et al. Evidence in Australia for a case of airport dengue. PLoS Negl Trop Dis. 2012;6:e1619.

30. Kushwah RB, Mallick PK, Ravikumar H, Dev V, Kapoor N, AdakTP, et al. Status of DDT and pyrethroid resistance in Indian Aedes albopictus and absence of knockdown resistance $(k d r)$ mutation. J Vector Borne Dis. 2015;52:95-8.

31. Kamgang B, Marcombe S, Chandre F, Nchoutpouen E, Nwane P, Etang $J$, et al. Insecticide susceptibility of Aedes aegypti and Aedes albopictus in Central Africa. Parasit Vectors. 2011:4:79.

32. Marcombe S, Farajollahi A, Healy SP, Clark GG, Fonseca DM. Insecticide resistance status of United States populations of Aedes albopictus and mechanisms involved. PLoS ONE. 2014;9:e101992.

33. Schmidt TL, van Rooyen AR, Chung J, Endersby-Harshman NM, Griffin PC, Sly A, et al. Tracking genetic invasions: genome-wide single nucleotide polymorphisms reveal the source of pyrethroid-resistant Aedes aegypti (yellow fever mosquito) incursions at international ports. Evol Appl. 2019. https://doi.org/10.1111/eva.12787.

34. Hamid PH, Ninditya VI, Prastowo J, Haryanto A, Taubert A, Hermosilla C. Current status of Aedes aegypti insecticide resistance development from Banjarmasin, Kalimantan, Indonesia. Biomed Res Int. 2018;2018:1735358.

35. Agresti A, Coull BA. Approximate is better than "Exact" for interval estimation of binomial proportions. Am Stat. 1998;52:119-26.

\section{Publisher's Note}

Springer Nature remains neutral with regard to jurisdictional claims in published maps and institutional affiliations.
Ready to submit your research? Choose BMC and benefit from:

- fast, convenient online submission

- thorough peer review by experienced researchers in your field

- rapid publication on acceptance

- support for research data, including large and complex data types

- gold Open Access which fosters wider collaboration and increased citations

- maximum visibility for your research: over 100M website views per year

At BMC, research is always in progress.

Learn more biomedcentral.com/submissions 